\title{
Optimal culture conditions and toxicity assessment of Fomitopsis feei (Fr.): a newly documented macro fungus from Philippines
}

\author{
De Leon $\mathrm{AM}^{1,2^{*}}$, Dulay $\mathrm{AR}^{1}$, Villanueva $\mathrm{AL}^{1}$ and Kalaw $\mathrm{SP}^{1,2}$ \\ ${ }^{1}$ Department of Biological Sciences, College of Science, Central Luzon State University, Science City of Muñoz, Nueva \\ Ecija, Philippines \\ ${ }^{2}$ Center for Tropical Mushroom Research and Development, Central Luzon State University, Science City of Muñoz, \\ Nueva Ecija, Philippines
}

De Leon AM, Dulay AR, Villanueva AL, Kalaw SP 2020 - Optimal culture conditions and toxicity assessment of Fomitopsis feei (Fr.): a newly documented macro fungus from Philippines. Studies in Fungi 5(1), 491-507, Doi 10.5943/sif/5/1/30

\begin{abstract}
Mushrooms are known to be utilized by ethnic communities and Paracelis, Mountain Province is one of the places in Philippines inhabited by several of these native groups. Many studies have been conducted on various macrofungi, however no studies have been reported about Fomitopsis feei in the Philippines particularly in Paracelis, Mountain Province. It is a brown-rot bracket fungus, belonging to the family Fomitopsidaceae, characterized by a sessile effuse-reflexed basidiomata, with its color ranging from white to pinkish or brown. This mushroom has been reported to have antimicrobial properties, hence optimization of its culture condition could lead to its mass production for its biopharmaceutical potential. In order to develop a mass cultivation protocol of this mushroom, this study was conducted to determine the optimum conditions for its mycelial growth. The effect of different culture media using local substrates and evaluating environmental factors such as $\mathrm{pH}$, aeration, illumination, and temperature were assessed. Optimum conditions for the secondary mycelial growth of $F$. feei produced very thick and largest radial growth on coconut water gelatin (CWG) medium $(83.57 \mathrm{~mm})$ at $\mathrm{pH} 6.5(83.13 \mathrm{~mm})$, in sealed (85 $\mathrm{mm})$, dark conditions $(85.00 \mathrm{~mm})$ at room temperature $\left(28-32^{\circ} \mathrm{C}\right)(81.96 \mathrm{~mm})$. The most abundant mycelial growth was found in cracked corn as grain spawning material. This study also determined the teratogenic and cytotoxic activity of the ethanol extract of $F$. feei against the zebra fish (Danio rerio) embryos and brine shrimp (Artemia salina) nauplii. Fomitopsis feei exhibited teratogenic effects against the developing $D$. rerio embryos wherein growth retardation, malformation of tail, yolk deformity, pericardial edema, curved body, scoliosis and little pigmentation were the notable teratogenic effects of the ethanol extract to the developing embryos. Embryos treated with $\geq 1000$ ppm recorded high mortality rate. Hatchability was most evident at lower concentrations $\leq 750 \mathrm{ppm}$. In terms of heartbeat, as the concentration of the extract increased, the heartbeat rate significantly decreased. For the cytotoxicity, $1250 \mathrm{ppm}$ has the highest mortality rate with $73.33 \%$. Using probit analysis, the $\mathrm{LC}_{50}$ is $534.676 \mathrm{ppm}$ which is considered as mildly toxic. Thus, F. feei in higher concentrations exhibit toxic effect. These results indicate that $F$. feei has a pharmaceutical potential and could be harnessed for its bioactivities.
\end{abstract}

Key words - cultivation - cytotoxicity - grain spawn - local substrate media - teratogenicity 


\section{Introduction}

Mushrooms are sources of food and nutrients and have high potential as sources of bioactive compounds with pharmaceutical effects (Oyetayo 2011). Numerous studies have discovered how mushrooms can be useful in preventing and treating health conditions. Ware (2017) reported that, some species of mushrooms have medicinal properties such as antioxidant, antimicrobial, anticancer, cholesterol lowering and decrease the risk of obesity, diabetes and heart disease. Also, several studies have been conducted related to species belonging to the genus Fomitopsis; this include the study of Cheng et al. (2008) on the medicinal importance of Fomitopsis pinicola as anti-microbial, anti-inflammatory, anti-tumor, antioxidant, anti-angiogenic and immune-stimulating effect. The fomitopsin isolated from Fomitopsis feei exhibited activity against Bacillus cereus and herpes simplex virus (Isaka et al. 2017). Culture filtrates of Fomitopsis feei in ten days incubated rice bran extract showed good antibacterial activity on Enterobacter aerogens, Bacillus subtilis, Microcococcus luteus and Proteus mirabilis (Hima et al. 2011). Additionally, polypore macrofungi have been reported to be used as herbal medicine for intermittent fever, chronic diarrhea, nervous, headache and jaundice (Rogers 2011). Moreover, Chilkov (2017) confirmed that, mushrooms such as Ganoderma reishi, Lentinula edodes, Trametes versicolor, Cordyceps sinensis, Grifola frondosa and Inonotus obliquus are rich in polysaccharides and beta glucans, which are considered as the primary active immune-enhancing constituents. Kumar (2015) noted that, mushrooms have become a source of food and drugs, and nutraceuticals due to their antioxidant, antitumor and antimicrobial properties. Research findings in the past three to four decades had demonstrated that mushrooms are important sources of pharmacological bioactive compounds that can enhance human health (Bankole \& Adekunle 2012). That is why determination of its bioactive constituents and its toxicity effect is crucial for the development of nutraceuticals. Raghunath \& Perumal (2016) noted that zebrafish embryo has emerged as a potential tool to test teratogenicity. As declared by Finn (2007), the developing zebrafish in an in vitro system has a lot of potentials in meeting the need of a simple and inexpensive test and rapid assay to determine the teratogenicity of a specific compound or chemical. Moreover, Reneses et al. (2016) revealed that the teratogenic activities of mushroom are important as some teratogens can be used as anticancer drugs. For the cytotoxicity, Syahmi et al. (2010) stated that brine shrimp bioassay is considered as a quick preliminary screening for the presence or absence of bioactivity and is also used to determine cytotoxicity. Likewise, Golla et al. (2011) specified that, brine shrimp lethality assay is a technique that requires small number of samples and is easily measured, has low-cost and utilizes small amount of test material.

The discovery of various novel bioactive compounds from wild macrofungi has been increasing for the last decades. Several studies have proven the significance of mushroom cultivation for environmental management and as a source of medicinal products that are rich in phytochemicals, antioxidant, bioactive and phenolic compounds found within different mushroom varieties (Chang \& Wasser 2012, Wasser 2010, 2014, Chang \& Wasser 2017). However, climate change, deforestation, and over exploitation of the forest might cause the occurrence of wild mushrooms to decrease, thus, cultivation of mycological wild resources is essential as a source of cell lines towards the effective utilization and conservation of mushrooms (Dulay et al. 2012). Also, ethnic communities from Paracelis, Mountain Province have been known to utilize different species of mushrooms. Hence, this study was conducted to optimize culture conditions and evaluate the possible toxic substances of Fomitopsis feei which was collected from Paracelis, Mountain Province using zebrafish and brine shrimp as animal models.

\section{Materials \& methods}

\section{Source of macrofungi}

Fomitopsis feei was collected from Paracelis, Mountain Province. The fruiting bodies were collected, wrapped in brown paper, labeled and were brought to the laboratory. 


\section{Preparation of culture media}

Thirty-nine grams of Potato Dextrose Agar (PDA) was boiled in $1000 \mathrm{ml}$ of distilled water, it was stirred thoroughly until the powder was dissolved. Homogenized culture medium was dispensed to glass bottles, plugged with cotton, covered with a clean paper, and sterilized at $121^{\circ} \mathrm{C}$ at 15 psi for 30 minutes. Then the medium was aseptically poured to sterile petri plates.

\section{Surface disinfection of mushroom tissues}

Fruiting body of $F$. feei was brushed to remove the dust. Then it was soaked with $10 \%$ sodium hypochlorite for 1 minute, then rinsed three times with distilled water.

\section{Mushroom tissue culture}

Fruiting body of $F$. feei was cut longitudinally in order to expose its inner portion. Using a sterile scalpel, a small portion was cut from the inner part of the mushroom tissue and then inoculated aseptically on the petri plates with the prepared PDA medium. Inoculated plates were incubated at room temperature until the mycelia has fully grown on the media surface.

\section{Screening of appropriate indigenous culture media for the mycelial growth of $F$. feei}

Various local substrates were used to prepare culture media in order to determine the most suitable media for $F$. feei growth. Each media was prepared with three replicates. The treatments used were the following: Potato Sucrose Gelatin (PSG), Coconut Water Gelatin (CWG), Rice Bran Decoction Sucrose Gelatin (RBDSG), Cracked Corn Decoction Sucrose Gelatin (CCDSG), and Taro Sucrose Gelatin (TSG). In the preparation of PSG and TSG, potato and taro were boiled separately in $1000 \mathrm{~mL}$ distilled water, filtered with cheese cloth, and the broths were adjusted to $\mathrm{pH} \mathrm{6.0,} \mathrm{mixed}$ with 20 g shredded gelatin bars. For the preparation of CCDSG and RBDSG, media were boiled in a $1000 \mathrm{~mL}$ distilled water, filtered, adjusted to $\mathrm{pH}$ 6.0, and decoctions were mixed with $20 \mathrm{~g}$ gelatin bars. For CWG, one liter of coconut water was filtered, boiled for 20 minutes, adjusted to $\mathrm{pH} 6.0$ and mixed with $20 \mathrm{~g}$ gelatin bars. All culture media were sterilized by autoclaving at $121^{\circ} \mathrm{C}(15 \mathrm{psi})$ for 15 minutes and pour plated. To assess the mycelial growth, $10 \mathrm{~mm}$ diameter mycelial plugs of $F$. feei was prepared using a cork borer and inoculated centrally on all culture media. All inoculated plates were incubated at room temperature and the mycelial growth diameter was measured and recorded daily. Mycelial density was also observed visually and rated as $(+)$ very thin, $(++)$ thin, $(+++)$ thick and $(++++)$ very thick. The best indigenous culture medium is defined as the medium that produced the most luxuriant mycelial growth in the shortest incubation period.

\section{Influence of physical factors on the mycelial growth of $F$. feei}

\section{pH}

As CWG was found to be the most suitable culture medium in terms of shortest incubation period with very thick mycelial density, its $\mathrm{pH}$ was adjusted in a range from 5.0, 5.5, 6.0, 6.5, 7.0, 7.5, and 8.0, pour plated and then inoculated with $F$. feei mycelia. Inoculated petri plates were then incubated at room temperature and the mycelial diameter was measured every 24 hours. Mycelial density and incubation period were also recorded.

\section{Aeration}

In the evaluation of the air requirement, the CWG medium was adjusted to the optimum $\mathrm{pH}$ 6.5. For sealed condition, layers of cling wrap were used while the other condition was left unsealed. Mycelial diameter and density were evaluated every 24 hours.

\section{Illumination}

To assess the influence of light in the mycelial growth of $F$. feei, $10 \mathrm{~mm}$ diameter mycelial plugs from cultures growing in CWG medium at $\mathrm{pH} 6.5$ were utilized. The inoculated petri plates were subjected to full lighted, full dark, and alternating light and dark conditions at room 
temperature. To facilitate the full lighted condition, a room with fluorescent light was used. In full dark, the petri plates were covered with clean black paper. While in alternating light and dark condition, inoculated plates were exposed to light for 12 hours with 12 hours of darkness. Each treatment was incubated at room temperature. Every 24 hours, mycelial diameter was measured and mycelial density was recorded.

\section{Temperature}

Mycelial plugs from CWG as the best culture medium, at $\mathrm{pH}$ 6.5, in sealed condition, incubated in total darkness were used to evaluate the temperature effect. Ten $\mathrm{mm}$ diameter of mycelial plugs were prepared using a sterile cork borer and incubated at the following conditions; room temperature, air-conditioned, and refrigerated. Mycelial diameter was measured every 24 hours and mycelial density were recorded.

\section{Evaluation of different granular materials for mother spawn production}

Various types of locally available granular materials (sorghum seeds, cracked corn, and palay seeds) for mother spawn production were evaluated for the mycelial growth of $F$. feei. The most suitable culture media and appropriate physical factors ( $\mathrm{pH}$, aeration, illumination and temperature) were used. Each treatment had three replicates. The treatment with the thickest mycelial density and with the shortest incubation period was identified as the best grain spawning material.

\section{Treatment preparation}

The procedure of Manasathien et al. (2012) with minor modification was used in this study. One $\mathrm{ml}$ of the mushroom extract was diluted in $9 \mathrm{ml}$ of embryo water for teratogenicity and saltwater solution for brine shrimp lethality assay. Three $\mathrm{ml}$ of each solution was used and each dose was evaluated in triplicates.

\section{Teratogenicity}

\section{Preparation of aquarium tank}

In order to maintain the adult female and male zebrafish a 1:2 ratio was used. A glass aquarium of approximately 5-gallon capacity containing untreated and clean tap water with continuous flow of oxygen via aerator were used.

\section{Zebrafish care, culture, and maintenance}

Healthy and sexually matured zebrafish were acquired from the Wet Laboratory of the College of Fisheries, CLSU. They were acclimatized for a week at room temperature condition before using for spawning and fertilization. The zebrafish was fed daily with flakes and the leftover food was removed daily for maintenance of water cleanliness and quality.

\section{Zebrafish spawning and egg production}

Zebrafish have daily cycle of light and darkness that affects their behavior and physiological function. The matured zebrafish was placed in a coarse plastic mesh submerged into the aquarium water to protect the eggs from being devoured by the matured zebrafish once fertilized. The zebrafish was then exposed to dark condition to stimulate spawning by covering the aquarium with a black plastic bag. The black plastic bag was removed after 12 hours of dark condition and the light was turned on to stimulate fertilization. Fertilized eggs were seen at the bottom of the aquarium with the aid of artificial light.

\section{Harvesting of fertilized eggs}

After 12 hours post fertilization, the fertilized eggs were collected and tapped out of the aquarium using a hose tube and transferred to a beaker. Morphological assessment was done before placing them in the vials wherein cloudy and ruptured eggs was discarded. 


\section{Zebrafish (Danio rerio) teratogenicity and toxicity assay}

Three milliliters of each treatment concentration were placed in each vial with four embryos at segmentation phase. Teratogenic activity was examined using a stereomicroscope after 12, 24, 36, and 48 hours of incubation. Morphological endpoint evaluation of zebrafish was based on the parameters established by Schulte \& Nagel (1994): lethal (coagulation, tail not detached, no somites, and no heartbeat), teratogenic (malformation of head and tail, scoliosis, growth retardation, stunted tail, and limited movement) and normal. Hatchability and mortality rate were recorded and pictures were taken out and death was defined as coagulated embryos.

\section{Cytotoxicity}

\section{Source of brine shrimp (A. salina) eggs}

Artemia cysts INVE brine shrimp eggs were acquired from the Wet Laboratory of College of Fisheries, CLSU.

\section{Hatching set-up}

A $1.5 \mathrm{~L}$ plastic bottle was cut at its base. The cut plastic bottle served as the hatchery vessel and was inversely hang on the hatching rack. The set-up was provided with proper illumination using 18-watt fluorescent bulb and was positioned 12 inches above the hatchery vessel to maintain the temperature to $28-30^{\circ} \mathrm{C}$. Aquarium air pump with air stone was placed at the bottom of the hatchery vessel for proper aeration.

\section{Hatching of brine shrimp eggs}

The hatchery was filled with artificial seawater prepared by dissolving $38 \mathrm{~g}$ of sea salt or rock salt in $1 \mathrm{~L}$ of distilled water following the method of McLaughlin \& Rogers (1998). One gram of brine shrimp eggs was hatched in the artificial seawater within 48 hours under illumination and with adequate aeration to keep the eggs in suspension until its 48 hours life. The hatchery was covered with thin gauze for protection against the entrance of undesirable insects or organisms that may be harmful to the developing eggs. The hatched eggs called nauplii were used for the assay.

\section{Brine shrimp lethality assay}

Using a hand lens, active 48-hour old nauplii were harvested and used for the assay. The larvae were transferred into each sample vials using a syringe. A drop of dry yeast suspension (3 mg yeast $/ 5 \mathrm{~mL}$ saline solution) was added to each vial as food of the nauplii and $200 \mu \mathrm{L}$ of different concentration was added. It was observed after 6, 12, 18, and 24 hours. The vials were maintained under illumination and dead nauplii were counted using a hand lens. The LC 50 was evaluated according to the rating of Aldahi et al. (2015) where $\mathrm{LC}_{50}$ of $<249 \mu \mathrm{g} / \mathrm{mL}$ as highly toxic, 250-499 $\mu \mathrm{g} / \mathrm{mL}$ is moderately toxic and $500-1000 \mu \mathrm{g} / \mathrm{mL}$ is mildly toxic. Values above $1000 \mu \mathrm{g} / \mathrm{mL}$ are nontoxic according to the rating of McLaughlin \& Rogers (1998).

\section{Statistical analysis}

All the treatments were arranged following the complete randomized design under laboratory conditions. One-way analysis of variance (ANOVA) was used to determine significant differences among treatments. Means were compared using least significant differences (LSD) at $5 \%$ level of significance. For the cytotoxicity, the median lethal concentration $\mathrm{LC}_{50}$ was computed using probit analysis. The SAS 9.1 program was used for the analyses.

\section{Results}

\section{Culture media}

Among the five evaluated culture media (PSG, CWG, RBDSG, CCDSG and TSG) CWG showed the largest mycelial growth diameter with $83.57 \mathrm{~mm}$, which was significantly higher than 
the other media after 12 days of incubation, while the smallest mycelial growth diameter was observed in PSG with $59.11 \mathrm{~mm}$ (Table 1). Moreover, CWG produced a very thick mycelial density, while CCDG have shown the thinnest mycelial density.

\section{pH levels}

No significant difference was found in the mycelial growth of $F$. feei in different $\mathrm{pH}$ levels (Table 1). However, pH 6.5 produced a thicker mycelial density compared to $\mathrm{pH}$ 6.0. The results revealed that the $\mathrm{pH}$ levels did not significantly affect the mycelial production of $F$. feei in the substrates. However, variation of growth of $F$. feei in mycelial density was evident at different $\mathrm{pH}$ levels. The results showed that $\mathrm{pH} 5.0$ to 8.0 could support an efficient mycelial growth of $F$. feei, but the range of $\mathrm{pH}$ 6.0-6.5 produced the highest mean mycelial growth.

\section{Aeration}

From the most appropriate medium and suitable $\mathrm{pH}$, the inoculated plates with $\mathrm{F}$. feei were sealed and the other were left unsealed in order to evaluate aeration requirements. The unaerated condition significantly recorded the maximum diameter of $85.00 \mathrm{~mm}$ in comparison to aerated condition with $80.97 \mathrm{~mm}$ (Table 1). Furthermore, mycelial density under sealed condition produced a very thick and cottony growth as compared to unsealed plates which exhibited only thick mycelial density.

Table 1 Mycelial diameter and density of $F$. feei on various nutritional and physical requirements for mycelial growth.

\begin{tabular}{lll}
\hline & Mycelial Diameter $(\mathbf{m m})$ & Mycelial Density \\
\hline Culture Media & & \\
PSG & $59.11 \pm 1.60^{\mathrm{c}}$ & ++ \\
CWG & $83.57 \pm 2.48^{\mathrm{a}}$ & +++ \\
RBDSG & $75.01 \pm 3.19^{\mathrm{b}}$ & ++ \\
CCDSG & $73.46 \pm 2.28^{\mathrm{b}}$ & + \\
TSG & $69.50 \pm 2.08^{\mathrm{b}}$ & ++ \\
\hline pH & & \\
5 & $82.05 \pm 1.72$ & ++ \\
5.5 & $79.62 \pm 2.04$ & ++ \\
6 & $83.22 \pm 2.04$ & +++ \\
6.5 & $83.13 \pm 2.94$ & ++++ \\
7 & $79.99 \pm 2.41$ & ++ \\
7.5 & $81.01 \pm 2.49$ & ++ \\
8 & $82.90 \pm 3.64$ & +++ \\
\hline Aeration & & +++ \\
Sealed & $85.00 \pm 0.00^{\mathrm{a}}$ & ++ \\
Unsealed & $80.97 \pm 0.67^{\mathrm{b}}$ & ++++ \\
\hline Illumination & & +++ \\
Dark & $85.00 \pm 0.00^{\mathrm{a}}$ & ++ \\
Light & $82.38 \pm 1.16^{\mathrm{b}}$ & +++ \\
Light and Dark & $81.90 \pm 1.17^{\mathrm{b}}$ & +++ \\
\hline Temperature & & - \\
Room Temperature & $81.96 \pm 2.73^{\mathrm{a}}$ & ++ \\
Air conditioned & $75.88 \pm 1.14^{\mathrm{b}}$ & +1 \\
Refrigerated & $10.00 \pm 0.00^{\mathrm{c}}$ & + \\
\hline
\end{tabular}

Values are means \pm sd; for each variable means with the same letters are not significantly different at $5 \%$ level using Tukey's HSD as post hoc. Note: $(+)$ very thin, $(++)$ thin, $(+++)$ thick, $(++++)$ very thick, $(-)$ no growth 


\section{Illumination}

F. feei mycelial diameter in dark condition registered a full growth of $85.00 \mathrm{~mm}$, analysis of variance showed that it is significantly higher than other treatments, while illuminated condition recorded a growth diameter of $82.38 \mathrm{~mm}$, while the least mycelial growth diameter was observed in alternating light and dark which has a mean mycelial growth of $81.90 \mathrm{~mm}$ (Table 1). A very thick mycelial density was also observed in the dark condition after 14 days incubation period and the alternating light and dark resulted to a thin mycelial growth.

\section{Temperature}

F. feei produced a very thick and cottony growth at room temperature $\left(28-33^{\circ} \mathrm{C}\right)$ as presented in Table 1. There was a significant difference between the mean mycelial growth diameter in room temperature $81.96 \mathrm{~mm}$ and air conditioned temperature $\left(18-24^{\circ} \mathrm{C}\right)$ with a mean of $75.88 \mathrm{~mm}$, while no growth was observed at refrigerated temperature $\left(8-10^{\circ} \mathrm{C}\right)$. At the same time, mycelial density at room temperature was recorded to be very thick, while mycelial density at air-conditioned temperature produced thick growth.

\section{Spawning Materials}

After 16 days of incubation, cracked corn showed the highest mycelial growth (Fig. 1), the sorghum seeds were colonized after 17 days, while there was a very thin growth in palay seeds.

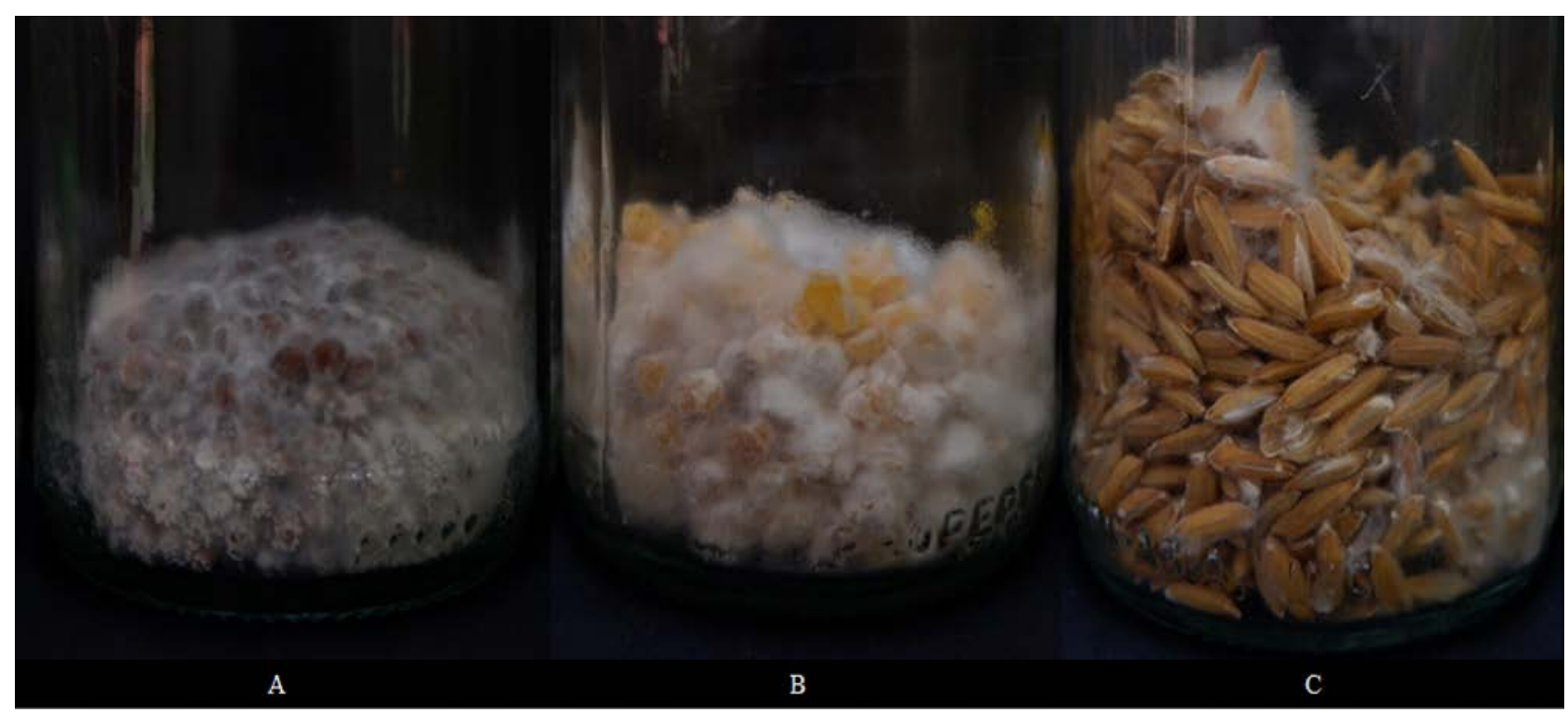

Fig. 1 - Mycelial density of F. feei in different spawning materials after 16 days. A Sorghum seeds. B Cracked corn. C palay seeds.

\section{Teratogenicity}

Teratogenic activities of $F$. feei ethanolic extract were evaluated using $D$. rerio embryos. Zebrafish embryos at segmentation phase exposed to different treatment concentrations (1250 ppm, 1000 ppm, 750 ppm, 500 ppm, 250 ppm, 100 ppm and 0 ppm) were examined under different developmental stages such as segmentation (12 hours post treatment application [hpta]), pharyngula (24-36 hpta) and hatching stage (48-72 hpta).

\section{Mortality}

Mortality is one of the parameters examined to determine the toxicity of the ethanolic extract of $F$. feei. It is described as having no observable heartbeat and coagulation. The toxic effect of $F$. feei was recorded and the mean percentage mortality of $D$. rerio embryos after $12,24,36$, and 48 hours of exposure in varying concentrations are shown in Table 2. No mortality was observed at 12- and 24-hours post treatment application (hpta) in all the treatments. However, longer duration 
of exposure of the embryos to the different concentrations of $F$. feei ethanol extract increased the percentage mortality and this was evident at $1250 \mathrm{ppm}$ and $1000 \mathrm{ppm}$ concentrations. Moreover, on $1250 \mathrm{ppm}$ concentration, a mean percentage mortality of $41.67 \%$ was recorded at 36 hpta and increased to $100 \%$ at 48 hpta. The mean percentage mortality for $1250 \mathrm{ppm}$ at 36 and 48 hpta was not significantly different with that of $1000 \mathrm{ppm}$ with a mean percentage mortality of 33.33\% observed at 36 hours and $100 \%$ on its 48 hours. However, the mean percentage mortality of $8.33 \%$ at 46 hpta on $750 \mathrm{ppm}$ was significantly different from that of the mean percentage mortality of 1250 and $1000 \mathrm{ppm}$. The toxic effects of the mushroom extract were dependent on the concentration and time of exposure, as shown by the increased mortality of embryos with higher level of concentration and longer time of exposure. No heartbeat was the most notable lethal effect of the ethanol extract exposed to 1250 ppm and 1000 ppm from 36 hours until 48 hours.

Table 2 Mean percentage mortality of Danio rerio embryos after 36, and 48 hours of exposure to different concentrations of Fomitopsis feei ethanol extract.

\begin{tabular}{lll}
\hline \multirow{2}{*}{ Concentration (ppm) } & \multicolumn{2}{l}{ Treatment Exposure } \\
\cline { 2 - 3 } & $\mathbf{3 6} \mathbf{~ h}$ & $\mathbf{4 8} \mathbf{~ h}$ \\
\hline 1250 & $41.67^{\mathrm{a}}$ & $100.00^{\mathrm{a}}$ \\
1000 & $33.33^{\mathrm{ab}}$ & $100.00^{\mathrm{a}}$ \\
750 & $0.00^{\mathrm{b}}$ & $8.33^{\mathrm{b}}$ \\
500 & $0.00^{\mathrm{b}}$ & $0.00^{\mathrm{b}}$ \\
250 & $0.00^{\mathrm{b}}$ & $0.00^{\mathrm{b}}$ \\
100 & $0.00^{\mathrm{b}}$ & $0.00^{\mathrm{b}}$ \\
0 & $0.00^{\mathrm{b}}$ & $0.00^{\mathrm{b}}$ \\
\hline
\end{tabular}

Means having the same letter of superscript in the same column are not significantly different at $\mathrm{P} \leq 0.05$ significance using LSD

\section{Hatchability}

Hatching is a significant key in successful embryonic developmental process. The percentage hatchability of embryos treated with different concentrations of lyophilized mushroom extract was observed (Table 3).

The $500 \mathrm{ppm}$ had the lowest mean percentage hatchability of $25 \%$. However, significant difference was observed between treatment concentrations $\geq 1000, \leq 750 \mathrm{ppm}$ and the control. Furthermore, no hatched embryo was recorded in $1250 \mathrm{ppm}$ and $1000 \mathrm{ppm}$ due to early death of embryos. It was observed that as the concentration of the ethanol extract decrease, the mean percentage hatchability of the embryos exposed on lower treatment concentrations increased. Thus, varying amount of the ethanol extract of $F$. feei affects the normal hatchability of the embryos exposed at 48 hours.

Table 3 Hatchability of embryos treated with different concentrations of Fomitopsis feei ethanol extract.

\begin{tabular}{ll}
\hline Concentration (ppm) & $\mathbf{4 8 ~ h}$ \\
\hline 1250 & $0.00^{\mathrm{b}}$ \\
1000 & $0.00^{\mathrm{b}}$ \\
750 & $41.67^{\mathrm{a}}$ \\
500 & $25.00^{\mathrm{a}}$ \\
250 & $41.67^{\mathrm{a}}$ \\
100 & $50.00^{\mathrm{a}}$ \\
Control & $41.67^{\mathrm{a}}$ \\
\hline
\end{tabular}

Means having the same letter of superscript in the same column are not significantly different at $\mathrm{P} \leq 0.05$ significance using LSD 


\section{Heartbeat rate}

The heartbeat rate of $D$. rerio was monitored microscopically at pharyngula stage (Table 4). The mean heartbeat rate of embryos exposed to $F$. feei ethanol extract was highest at $100 \mathrm{ppm}$ with 202 beats per minute and was significantly different from that of the mean percentage heartbeat of 1250 ppm with only 154 beats per minute. It can be marked that the different concentrations of $F$. feei extract affects the heartbeat of zebrafish embryos.

Table 4 Heartbeat of Danio rerio after 36 hours of exposure to various concentrations of Fomitopsis feei ethanol extract.

\begin{tabular}{ll}
\hline Concentration (ppm) & Heartbeat \\
\hline 1250 & $154.00^{\mathrm{cd}}$ \\
1000 & $128.00^{\mathrm{d}}$ \\
750 & $182.00^{\mathrm{abc}}$ \\
500 & $160.00^{\mathrm{bc}}$ \\
250 & $186.00^{\mathrm{ab}}$ \\
100 & $202.00^{\mathrm{a}}$ \\
Control & $188.00^{\mathrm{ab}}$ \\
\hline
\end{tabular}

Means having the same letter of superscript in the same column are not significantly different at $\mathrm{P} \leq 0.05$ significance using LSD

\section{Morphological endpoints of treated $D$. rerio embryos}

Parameters such as head and tail malformation, growth retardation, and little pigmentation were used as parameters in order to evaluate the teratogenic effects of the extract after $12,24,36$, and 48 hours of exposure as presented on Table 5.

\section{Growth retardation}

The most prominent observed teratogenic effects of $F$. feei ethanol extract was growth retardation. It was distinguishable on embryos treated with $750 \mathrm{ppm}$.

\section{Morphological abnormalities}

Lethal and teratogenic effects exhibited by $F$. feei ethanol extract on developing embryos at various concentrations at different hours of exposure are presented in Figure 2. Ethanol extract of F. feei resulted to curved body which was notable in $750 \mathrm{ppm}$ concentration at 48 hpta (Figure 2A). Yolk deformity of the embryo was also observed in $750 \mathrm{ppm}$ concentration at 48 hpta (Figure 2B). The only observed tail malformation was bent tail (Figure 2B) in $750 \mathrm{ppm}$ concentration at 48 hpta. Moreover, scoliosis can be seen prominent (Figure 2C) in 750 ppm concentration at 48 hpta. Furthermore, little pigmentation, no gut and pericardial edema were the other observed morphological abnormalities. Pericardial edema and little pigmentation (Figure 2D) was observed at 48 hpta in 500 ppm.

Table 5 Lethal and teratogenic effects of various concentrations of $F$. feei ethanol extract at 12, 24, 36, and 48 hours of exposure.

\begin{tabular}{llllllllll}
\hline Toxicological & Time of Exposure & \multicolumn{8}{l}{ Concentration $(\mathbf{p p m})$} \\
\cline { 3 - 8 } Endpoints & $(\mathbf{h})$ & $\mathbf{1 2 5 0}$ & $\mathbf{1 0 0 0}$ & $\mathbf{7 5 0}$ & $\mathbf{5 0 0}$ & $\mathbf{2 5 0}$ & $\mathbf{1 0 0}$ & $\mathbf{0}$ \\
\hline Lethal & & - & - & - & - & - & - & - \\
Coagulation & 12 & - & - & - & - & - & - & - \\
& 24 & - & - & - & - & - & - & - \\
& 36 & - & - & - & - & - & - & - \\
No heartbeat & 48 & - & - & - & - & - & - & - \\
& 12 & - & - & - & - & - & - & - \\
& 24 & + & + & - & - & - & - & - \\
\hline
\end{tabular}


Table 5 Continued.

\begin{tabular}{|c|c|c|c|c|c|c|c|c|}
\hline \multirow{2}{*}{$\begin{array}{l}\text { Toxicological } \\
\text { Endpoints }\end{array}$} & \multirow{2}{*}{$\begin{array}{l}\text { Time of Exposure } \\
\text { (h) }\end{array}$} & \multicolumn{7}{|c|}{ Concentration (ppm) } \\
\hline & & 1250 & 1000 & 750 & 500 & 250 & 100 & $\mathbf{0}$ \\
\hline & 48 & + & + & + & - & - & - & - \\
\hline \multicolumn{9}{|l|}{ Teratogenic } \\
\hline \multirow[t]{4}{*}{ Malformation of head } & 12 & - & - & - & - & - & - & - \\
\hline & 24 & - & - & - & - & - & - & - \\
\hline & 36 & - & - & - & - & - & - & - \\
\hline & 48 & - & - & - & - & - & - & - \\
\hline \multirow[t]{4}{*}{ Malformation of tail } & 12 & - & - & - & - & - & - & - \\
\hline & 24 & - & - & - & - & - & - & - \\
\hline & 36 & - & - & - & - & - & - & - \\
\hline & 48 & - & - & + & - & - & - & - \\
\hline \multirow[t]{4}{*}{ Scoliosis } & 12 & - & - & - & - & - & - & - \\
\hline & 24 & - & - & - & - & - & - & - \\
\hline & 36 & - & - & - & - & - & - & - \\
\hline & 48 & - & - & + & - & - & - & - \\
\hline \multirow[t]{4}{*}{ Growth retardation } & 12 & - & - & - & - & - & - & - \\
\hline & 24 & - & - & - & - & - & - & - \\
\hline & 36 & - & - & - & - & - & - & - \\
\hline & 48 & - & - & + & - & - & - & - \\
\hline \multirow[t]{4}{*}{ Limited movement } & 12 & - & - & - & - & - & - & - \\
\hline & 24 & - & - & - & - & - & - & - \\
\hline & 36 & - & - & - & - & - & - & - \\
\hline & 48 & - & - & - & - & - & - & - \\
\hline \multirow[t]{4}{*}{ Little pigmentation } & 12 & - & - & - & - & - & - & - \\
\hline & 24 & - & - & - & - & - & - & - \\
\hline & 36 & - & - & - & - & - & - & - \\
\hline & 48 & - & - & + & + & - & - & - \\
\hline
\end{tabular}

+ indicates presence of lethal or teratogenic effects to developing embryos at various observation hours

- indicates absence of lethal or teratogenic effects to developing embryos at various observation hours

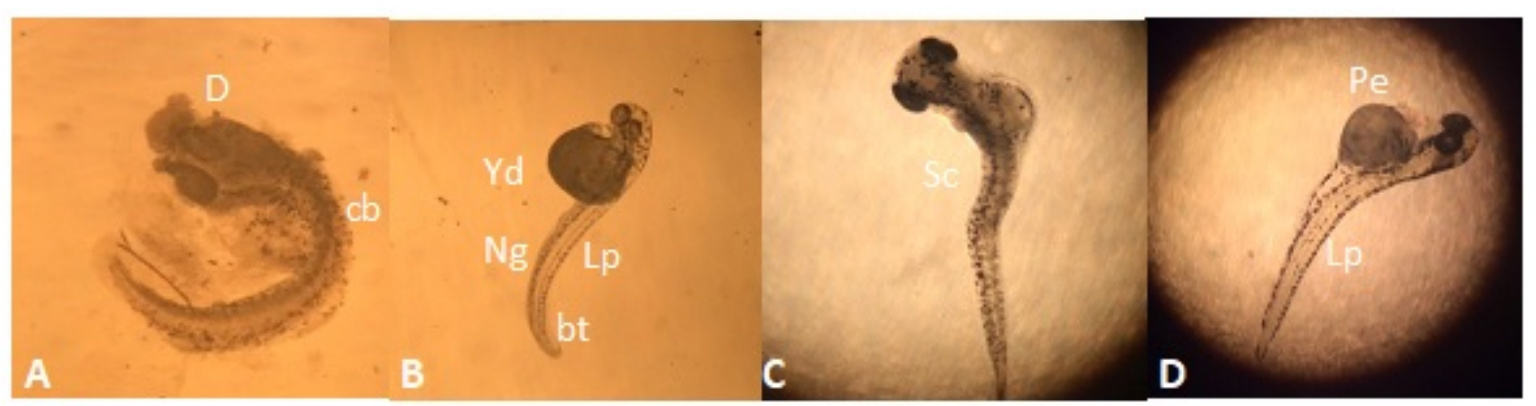

Fig. 2 - Lethal and teratogenic effects of various concentrations of $F$. feei ethanol extract. A dead embryo (D) and curved body (cb) at $48 \mathrm{hpta}$ in $750 \mathrm{ppm}$. B yolk deformity (Yd), no gut (Ng), little pigmentation (Lp) and bent tail (bt) at 48 hpta in 750 ppm. C scoliosis (Sc) at 48 hpta in 750 ppm. $\mathrm{D}$ pericardial edema (Pe) and little pigmentation (Lp) at $48 \mathrm{hpta}$ in $500 \mathrm{ppm}$.

\section{Cytotoxicity}

Brine shrimp lethality was used in order to determine the cytotoxic activity of $F$. feei. Table 6 shows the mean percentage mortality of $A$. salina nauplii after 24 hours of exposure to different concentrations of $F$. feei ethanol extract. 
It can be seen that $1250 \mathrm{ppm}$ recorded the highest mortality rate with $73.33 \%$ while $100 \mathrm{ppm}$ registered the lowest mortality rate with $26.67 \%$. Analysis of variance (ANOVA) shows that after 24 hours of exposure to the extract, there was no significant difference among treatment concentrations $\geq 1000 \mathrm{ppm}$. However, significant difference was observed between $1250 \mathrm{ppm}$ and concentrations $\leq 750 \mathrm{ppm}$ and the control.

Using probit analysis, Fig. 3 shows the median lethal concentration $\left(\mathrm{LC}_{50}\right)$ of the F. feei ethanol extract. It was estimated that the $\mathrm{LC}_{50}$ of $F$. feei ethanol extract is $534.676 \mathrm{ppm}$ which is considered to be mildly toxic based on the ratings of Aldahi et al. (2015).

Table 6 Mean percentage mortality of A. salina nauplii after 24 hours of exposure to different concentrations of $F$. feei ethanol extract.

\begin{tabular}{ll}
\hline Concentration (ppm) & Mortality (\%) \\
\hline 1250.00 & $73.33^{\mathrm{a}}$ \\
1000.00 & $66.67^{\mathrm{a}}$ \\
750.00 & $50.00^{\mathrm{b}}$ \\
500.00 & $43.33^{\mathrm{b}}$ \\
250.00 & $26.67^{\mathrm{c}}$ \\
100.00 & $26.67^{\mathrm{c}}$ \\
0.00 & $0.00^{\mathrm{d}}$ \\
\hline
\end{tabular}

Means having the same letter of superscript in the same column are not significantly different at $\mathrm{P} \leq 0.05$ significance using LSD

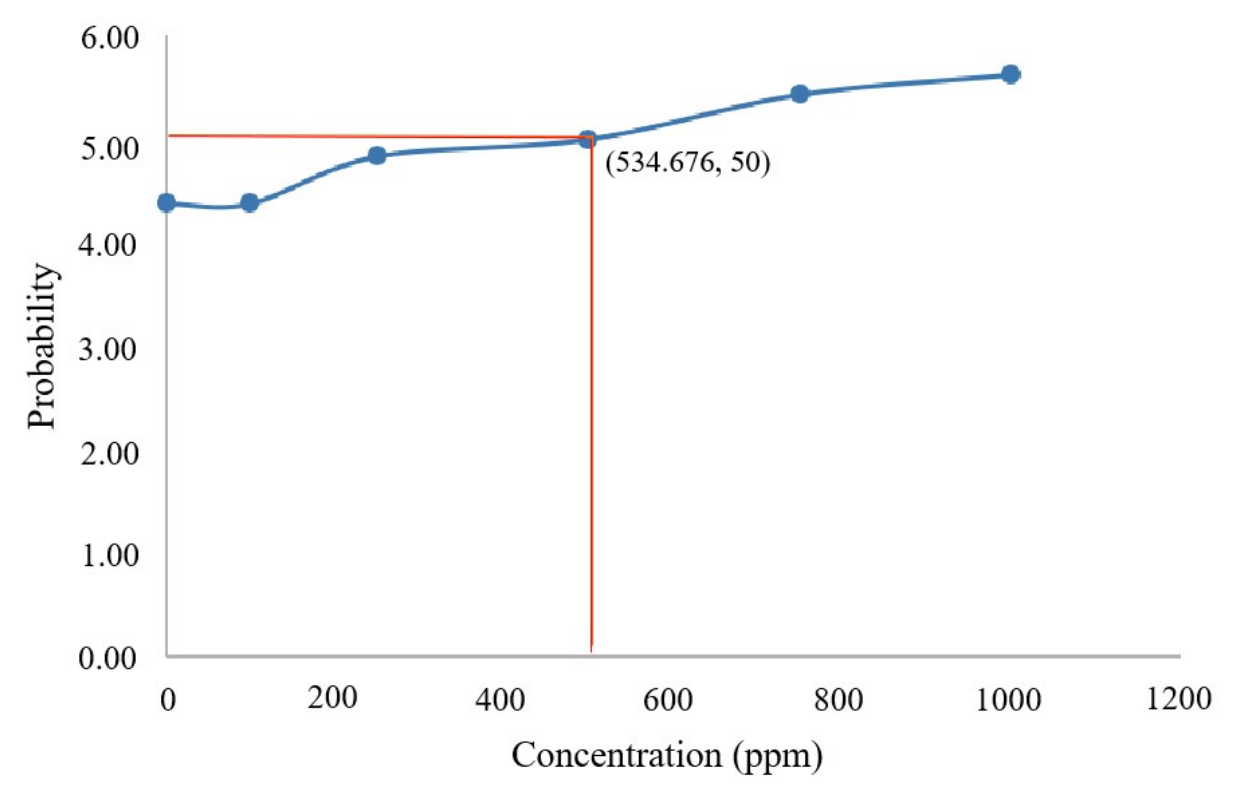

Fig. 3 - Point estimate of LC50 value of Fomitopsis feei ethanol extract after 24 hours of exposure.

\section{Discussion}

Several studies have been conducted about Fomitopsis feei in India but none in the Philippines. This mushroom was reported to exhibit different biological activities such as antibacterial, antifungal, antioxidant and 5-lipoxygenase, alpha glucosidase and tyrosinase enzyme inhibitory activities using exopolysaccharide (Bindu \& Charya 2017a). This mushroom contains essential amino acids such as arginine which play an important role in the activity of macrophages and considerable amount of linolenic acid which are essential for human health (Bindu \& Charya 2017b). Furthermore, this mushroom also exhibited lignolytic enzyme activities, which can be used in biobleaching and dye reduction industries (Bindu et al. 2011). Since F. feei can decolorize several synthetic dyes belonging to triphenylmethane group efficiently (Lyra et al. 2009), it can be 
used in biological treatment to control pollution generated by textile and dye-stuff industries (Bindu et al. 2013). With these significant functionalities of $F$. feei reported in other countries, it is of utmost importance that the culture conditions of this mushroom be optimized under Philippine condition to harness its potential in the nutraceutical industry.

\section{Nutritional and environmental factors affecting mycelial growth of $F$. feei}

In mushroom production, mushroom tissue culture is highly important for it is the source of mycelia and mushroom cell lines. Hence, the nutritional composition of the culture medium is one of the factors to be considered in mycelial production (De Leon et al. 2013). Nutrients present in the culture medium and environmental conditions are one of the major factors in the growth of mushrooms (Thongklang et al. 2010). The growth of $F$. feei was recorded to be abundant and very thick in the CWG medium. The abundance of the growth in CWG can be attributed to its nutritional content such as sugars, vitamins, minerals, and amino acids, with nitrogen (0.62\%), phosphorus $(0.36 \%)$, potassium $(2.36 \%)$, sulfur $(1.64 \%)$, sodium $(0.86 \%)$, calcium $(0.1 \%)$, magnesium (0.48\%), zinc $(20.6 \%)$, copper $(17.4 \%)$, iron $(93.2 \%)$, manganese $(84 \%)$ (Umesha \& Naranayaswamy 2016). The presence of sugar in CWG medium accords with the report of Bindu \& Charya (2017c) that glucose as carbon source $(6.88 \mathrm{~g} / \mathrm{L}, 6.04 \mathrm{~g} / \mathrm{L})$ yielded the best mycelial biomass of $F$. feei both in 7 and 14 days respectively. In congruence with the study of De Leon et al. (2017) wherein Lentinus sajor-caju was reported to have the highest mycelial growth diameter in CWG with $88.75 \mathrm{~mm}$. Same is true with the study of Kalaw et al. (2016) in which CWG significantly showed the largest mycelial growth diameter with ten mushroom species assessed. Furthermore, similar studies by Magday et al. (2014) have proven that CWG was the most suitable culture medium for several mushroom species like Ganoderma lucidum. On the other hand, growth pattern of $F$. feei mycelia in commercial solid media was found to be good in malt extract agar (MEA) (Bindu \& Charya 2017b).

Furthermore, various environmental conditions were found to affect the mycelial growth including $\mathrm{pH}$, aeration, light, and temperature as previously recorded (Shah \& Modi 2018, Stott \& Mohammed 2004). Results showing that the range of $\mathrm{pH}$ 6.0-6.5 produced the highest mean mycelial growth for F. feei is in accordance to the study of Bindu \& Charya (2017c) that pH 6.0 is the most suitable $\mathrm{pH}$ level for the exopolysaccharide production from mycelial production of $F$. feei and F. pinicola (Dubok et al. 2007). Similar findings were reported by Magday et al. (2014) that a slightly acidic $\mathrm{pH}$ of 6.0 and 6.5 could support a rapid and thick mycelial growth of G. lucidum, similarly, low pH levels like 5.0 supports the growth of Stropharia rugosoannulata and Pleurotus ostreatus (Furlan et al. 1997). The luxuriant growth in unaerated condition is congruent to the observartion of Chang \& Miles (2004) that oxygen and carbon dioxide are the components of air that are significant to the growth of most fungi. Similar to what this present study has revealed, Lentinus squarrosulus incubated at sealed conditions also produced larger mycelial growth (De Leon et al. 2017), possibly, due to high concentration of $\mathrm{CO}_{2}$, the rate of the mycelial growth is triggered. In accordance with the study of Magday et al. (2014), wherein rich biomass production was also observed with G. lucidum in sealed condition. Moreover, assessment of the effect of illumination is necessary to determine the most suitable environmental condition for mycelial growth (Chang \& Miles 2004). Results showing that total darkness influenced the mycelial growth of $F$. feei as it showed thickest mycelial density and rapid incubation period is similar with the study of Kalaw et al. (2016) wherein dark conditions proved maximum growth for G. lucidum strain B, L. tigrinus CLSU strain, G. lucidum strain A, L. tigrinus CLSU strain, and Coprinopsis cinerea Sto. Domingo strain. This also conforms to the study of Reyes et al. (2009), which shows that light is not essential for the growth of Coprinus comatus, as well as in the growth of Paneolus cyanescens and Paneolus antillarium (Bustillos et al. 2014). Better growth of mushroom in darkness was also observed in Laricifomes officinalis (Zhu Na et al. 2011) and L. sajor-caju (Cuevas et al. 2009). According to Chang \& Miles (2004), light might hinder the ramification or even cause the death of mycelia in strong light conditions. Another ecological factor that affects mushroom growth is temperature (Bellettini et al. 2019). The result of this study is supported by the 
study of Bindu \& Charya (2017a) wherein, the abundance of mycelial growth and exopolysaccharide production of $\mathrm{F}$. feei was found at $30^{\circ} \mathrm{C}$, while $\mathrm{F}$. pinicola was observed to have maximum mycelial growth at $25^{\circ} \mathrm{C}$ (Dubok et al. 2007). This also conforms with the study of Jacob et al. (2015) wherein three species of mushroom; Pleurotus citrinopileatus, Pleurotus djamor and Pleurotus salmoneostramineus, grew best at room temperature. Similarly, in terms of the growth at refrigerated condition, the present study is congruent to the report of Lee et al. (2008). Thus, temperature greatly affects growth of mycelia (Kalaw et al. 2016). Additionally, the quality of spawning material contributes the most in the production of macrofungi (Awi-Waadu \& Stanley 2010). In terms of the spawn evaluation, the luxuriant and fast mycelial growth in corn grits is similar to the results obtained by Magday et al. (2014), in which G. lucidum exhibited a robust growth in corn grits, fully colonizing the substrate within five-days incubation period. These results suggest that the protein, fatty acid, and high carbohydrate content of cracked corn enhances the growth of F. feei mycelia.

\section{Teratogenicity}

The result of the study wherein the toxic effects of the $F$. feei ethanolic extract was dependent on the concentration and time of exposure is in conformity with the findings of Bustillos et al. (2016), who reported that prolonged period at higher concentration of $P$. antillarium and $P$. cyanescens extracts increased the mortality of zebrafish embryos. The study of Reneses et al. (2016) also suggested that $L$. sajor-caju exhibited toxic and teratogenic effects to zebrafish embryo as a $100 \%$ mortality was observed at $3 \%$ and $1 \%$ extract concentrations and at $0.5 \%$ extract concentration after 36 hours and 48 hours, respectively. Moreover, Dulay et al. (2017), disclosed no mortality to embryos at $0.10 \%$ and lower concentrations of $V$. volvacea. In terms of hatchability it was observed that as the concentration of the ethanol extract decrease, the mean percentage hatchability of the embryos exposed on lower treatment concentrations increased. Thus, varying amount of the ethanol extract of $F$. feei affects the normal hatchability of the embryos exposed at 48 hours. In line with this, De Castro et al. (2016), found out that the effect of the extract is dose dependent. The treated embryos with higher concentrations of T. clepeatus ethanol extract was said to be significantly different from that of the control. De Castro \& Dulay (2015), also reported that the effect of ethanol extracts from $L$. sajor-caju and $P$. ostreatus in $D$. rerio embryos were dependent on concentration and period of exposure. Based on the results obtained, several factors such as antioxidants could probably affect the hatching time of zebrafish embryo. Thus, the success of hatching rate of the $F$. feei ethanol extract may be attributed to some of its functional components. Moreover, the normal embryonic heartbeat rate in zebrafish is much closer to that of humans, at 120-180 beats per minute (Mabley \& Childs 2010). Evaluation of heartbeat shows that as the concentration of the $F$. feei ethanolic extract increased, the heartbeat rate significantly decreased. These results are correlated with the findings of Dulay et al. (2014), wherein the extract of Lentinus tigrinus induce a significant decreased in heartbeat rate at $5 \%$ or higher concentrations. Furthermore, growth retardation is the most prominent teratogenic effect of $F$. feei ethanolic extract. Similarly, the major teratogenic effects of $L$. sajor-caju and P. ostreatus ethanol extract is delayed growth (De Castro \& Dulay 2015). This is also correlated with the study of Dulay et al. (2012), wherein growth retardation was evident among embryos exposed to 5\%, $10 \%$ and $20 \%$.

\section{Cytotoxicity}

The brine shrimp lethality assay showed that F. feei in higher concentrations exhibited toxic effect. This is an interesting finding since some anti-cancer drugs are known to be cytotoxic. These results could be correlated to the study of Shnyreva et al. (2018), wherein F. pinicola exhibited cytotoxicity against Jukart leukemia cell line. Additionally, Wu et al. (2014) showed that $F$. pinicola exerted anti-cancer effect against cancer cell lines since its ethanol extract induces cell apoptosis to exert significant anti-tumor activity. Furthermore, the study of Younis et al. (2014) showed that Lentinula edodes extract exhibited high toxicity in human liver carcinoma cell line and concluded that mushrooms could be a source of antitumor compounds. Similarly, Badshah et al. 
(2015) reported that Astraeus hygrometricus and Calvatia gigantea have high phenolic content and total antioxidant activity as well as brine shrimp cytotoxicity. Therefore, the bioactive compounds present in F. feei could be harnessed for its pharmaceutical potential.

\section{Acknowledgements}

The authors would like to thanks the people of Paracelis, Mountain Province, for allowing them to collect samples in the area. They also thank Emerson Diego, Lois Kristien Domingo, Bryan Panto, Mariane Ann Pagaduan, Larny Martin and Jessa Mae Domingo.

\section{References}

Aldahi A, Khalid H, Alhassan M, Ali A et al. 2015 - Antioxidant and cytotoxic activity of Cordia africanian Sudan. Advancement in Medical Plant Research 3(2), $29-32$.

Awi-Waadu GD, Stanley OH. 2010 - Effect of substrates of spawn production on mycelial growth of oyster mushroom species. Research Journal of Applied Sciences 5(3), 161-164.

Badshah H, Ullah F, Khan MU, Mumtaz AS, Malik RN. 2015 - Pharmacological activities of selected wild mushrooms in South Waziristan, Pakistan. South African Journal of Biology 97, 107-110.

Bankole PO, Adekunle AA. 2012 - Studies on biodiversity of some mushrooms collected in Lagos State, Nigeria using biotechnological methods. Journal of Yeast and Fungal Research 3 (4): 37-48.

Bellettini MB, Assumpc F, Fiorda A, Maieves HA et al. 2019 - Factors affecting mushroom Pleurotus spp. Saudi Journal of Biological Sciences 26, 633-646.

Bindu NH, Bolla K, Metuku RP, Burra S et al. 2011 - Enzymatic and Biological Activities of Fomitopsis feei in Broth Media Supplemented with Agricultural Wastes. Journal of Recent Advances in Applied Sciences 26:19-26.

Bindu H, Charya MAS. 2017a - Biological Activities of Exopolysaccharide from Fomitopsis feei. International Journal of Microbiological Research 8 (2): 48-58.

Bindu H, Charya MAS. 2017b - Growth Pattern, Molecular Identification and Bio molecules Analysis of Fomitopsis feei. Invention Journal of Research Technology in Engineering \& Management 1 (9): 16-26.

Bindu H, Charya MAS. 2017c - Physiological studies on mycelial growth and exopolysaccharide production by Fomitopsis feei. International Journal of Current Microbiology and Applied Sciences 6(6), 743-755.

Bindu NH, Gudikandula K, Pabba SK, Maringanti SC. 2013 - Decolorization of triphenyl methane dyes by Fomitopsis feei. Natural Science 5 (6a): 30-35.

Bustillos RG, Paguio ZK, Hermosa DP, Dulay RMR. 2016 - Philippine coprophilus mushrooms (Panaeolus antillarium and Panaeolus cyanescens) exhibit toxic and teratogenic effects in zebrafish (Danio rerio) embryo model. Advances in Environmental Biology 10(3), 75-80.

Bustillos RG, Dulay RMR, Kalaw SP, Reyes RG. 2014 - Optimization of culture conditions for mycelia growth and basidiocarp production of Philippine strains of Panaelus antillarium and Panaelus cyanescens. Mycosphere 5(3), 398-404.

Chang ST, Miles PG. 2004 - Mushroom cultivation, nutritive value, medicinal effect and environmental impact. CRC press 2, 477.

Chang ST, Wasser SP. 2017 - The Cultivation and environmental impact of mushrooms. Retrieved from:

https://oxfordre.com/environmentalscience/view/10.1093/acrefore/9780199389414.001.0001/ acrefore-9780199389414-e-231.

Chang ST, Wasser SP. 2012 - The role of culinary-medicinal mushrooms on human welfare with a pyramid model for human health. International Journal of Medicinal Mushrooms 14(2), 93134. 
Cheng JJ, Lin C, Lur H, Chen H, Lu M. 2008 - Properties and biological functions of polysaccharides and ethanolic extracts isolated from medicinal fungus, Fomitopsis pinicola. Process Biochemistry 43(8), 829-834.

Chilkov N. 2017 - Six cancer-fighting medicinal mushrooms. Huffpost: The Blog. Retrieved from https://www.huffingtonpost.com/nalini-chilkov/cancer-foods_b_1192207.html.

Cuevas MJ, Reyes R, Kalaw SP. 2009 - Biophysiology of Lentinus sajor-caju. Journal of Tropical Biology 7, 48.

De Castro MEG, Dulay RMR, Enriquez MLD. 2016 - Toxic and teratogenic effects of medicinal and culinary mushroom, Termitomyces clypeatus, collected from the termite mound in Mt. Makiling forest reserve, Los Baños, Laguna, Philippines on developing embryos of zebrafish (Danio rerio). Scholars Research Library 8(5), 237-242.

De Castro MEG, Dulay RMR. 2015 - Toxic and teratogenic effects of Lentinus sajor-caju and Pleurotus ostreatus ethanolic extracts in Danio rerio embryo model. International Journal of Biology, Pharmacy and Allied Sciences 4(4), 2261-2269.

De Leon AM, Orpilla JOV, Cruz KV, Dulay RM et al. 2017 - Optimization of mycelial growth and mycochemical screening of Lentinus sajor-caju (fr.) from Banaue, Ifugao province, Philippines. International Journal of Agricultural Technology 13(7.3), 2549-2567.

De Leon AM, Reyes RG, Dela Cruz TEE. 2013 - Enriched cultivation of three wild strains of Lentinus tigrinus (Bull.) fr. using agricultural wastes. Journal of Agricultural Technology 9(5), 1199-1214.

Dubok C, Maeng JM, Ding JL, Chaj WS. 2007 - Exopolysaccharide production and mycelial growth in an air-lift bioreactor using Fomitopsis pinicola. Microbiology and Biotechnology 17(8), 1369-1378.

Dulay RMR, Kalaw SP, Reyes RG, Alfonso NF, Eguchi F. 2012 - Teratogenic and toxic effects of Lingzhi or Reishi medicinal mushroom, Ganoderma lucidum (W.Curt.:Fr.) P. Karst (higher basidiomycetes), on zebrafish embryo as model. International Journal of Medicinal Mushrooms 14(5), 507-512.

Dulay RMR, Kalaw SP, Reyes RG, Cabrera EC. 2014 - Embryo-toxic and teratogenic effects of Philippine strain of Lentinus tigrinus (tiger sawgill basidiomycetes) extract on zebrafish (Danio rerio) embryos. Annals of Biological Research 5(6), 9-14.

Dulay RMR, Rivera AC, De Castro MEG. 2017 - Wild paddy straw mushroom (Volvariella volvacea) exhibit toxic and teratogenic effects in zebrafish (Danio rerio) embryo. International Journal of Biology, Pharmacy and Allied Sciences 6(5), 910-917.

Finn RN. 2007 - The physiology and toxicology of salmonid eggs and larvae in relation to water quality criteria. Aquatic Toxicology 81(4), 337-354.

Furlan SA, Virmond LJ, Miers DA, Bonatti M et al. 1997 - Mushroom strains able to grow at high temperatures and low pH values. World Journal of Microbiology and Biotechnology 13, 689692.

Golla UR, Gajam PK, Mohammad AR, Kumar KA, Raj BSS. 2011 - Assessment of bioactivity of Desmostachya bipinnata (L.) Stap using brine shrimp (Artemia salina) lethality assay. Pharmacology online 3, 982-990.

Hima SVSSSL, Nidadavolu B, Bolla K, Metuku RP et al. 2011 - Enzymatic and Biological Activities of Fomitopsis feei in Broth Media Supplemented with Agricultural Waste. Journal of Recent Advances in Applied Sciences 26, 19-26.

Isaka M, Chinthanom P, Srichomthong K, Thummarukcharoen T. 2017 - Lanostane triterpenoids from fruiting bodies of the bracket fungus Fomitopsis feei. Tetrahedron Letters 58(18), 17581761.

Jacob JKS, Kalaw SP, Reyes RG. 2015 - Mycelial growth performance of three species of Pleurotus on coconut water gelatin. Current Research in Environmental \& Applied Mycology 5(3), 263-268. 
Kalaw SP, Alfonso DO, Dulay RMR, De Leon AM et al. 2016 - Optimization of culture conditions for secondary mycelial growth of wild macrofungi from selected areas in Central Luzon, Philippines. Current research in environmental \& applied mycology 6(4), 277-287.

Kumar K. 2015 - Role of edible mushrooms as functional foods- a review. South Asian Journal Food Technology Environment 1, 211-218.

Lee UY, Jayasinghe C, Imtiaj A, Hur H et al. 2008 - Favorable culture conditions for mycelial growth of korean wild strains in Ganoderma lucidum. Mycobiology 36, 28 -33.

Lyra ES, Moreira KA, Porto TS, Carneiro da Cunha MN et al. 2009 - Decolorization of synthetic dyes by basidiomycetes isolated from woods of the Atlantic Forest (PE). Brazilian World Journal of Microbiology and Biotechnology 25, 1499-1504.

Mabley JD, Childs SJ. 2010 - “Zebrafish Cardiovascular System”. Fish Physiology, New York City: Academic Press 29, 141-159.

Magday Jr JC, Bungihan ME, Dulay RMR. 2014 - Optimization of mycelial growth and cultivation of fruiting body of Philippine wild strain of Ganoderma lucidum. Current Research in Environmental \& Applied Mycology 4(2), 162-172.

Manasathien J, Indrapichate K, Intarapichet K. 2012 - Antioxidant activity and bioefficacy of pomegranate Punica granatum Linn. Peel and seed extracts. Global Journal of Pharmacology 6(2), 131-141.

Mclaughlin JL, Rogers LL, Anderson JE. 1998 - The use of biological assays to evaluate botanicals. Drug information journal 32(2), 513-524.

Oyetayo OV. 2011 - Medicinal uses of mushrooms in Nigeria: Towards full and sustainable exploitation. African Journal of Traditional, Complementary and Alternative Medicines 8(3), 267-274.

Raghunath A, Perumal E. 2016 - Analysis of lethality and malformations during zebrafish (Danio rerio) development teratogenicity testing. Methods in Molecular Biology 337-363.

Reneses MAM, Dulay RMR, De Leon AM. 2016 - Proximate nutritive composition and teratogenic effect of Lentinus sajor-caju collected from Banaue, Ifugao Province, Philippines. International Journal of Biology, Pharmacy and Allied Sciences 5(7), 1771-1786.

Reyes RG, Lopez LMA, Kumakura L, Kalaw SP, Kikukawa TEF. 2009 - Coprinus comatus, a newly domesticated wild nutriceutical mushroom in the Philippines. Journal of Agricultural Technology 5(2), 299-316.

Rogers R. 2011 - Three under-utilized medicinal polypores. Journal of the American Herbalist Guild 12(2), 15-21.

Schulte C, Nagel R. 1994 - Testing acute toxicity in the embryo of zebrafish, Brachydanio rerio, as an alternative to the acute fish test: preliminary results. Association of Live Animals 22, 12 19.

Shah P, Modi HA. 2018 - Optimization of culture conditions for biomass production of Ganoderma lucidum. International Journal of Current Microbiology and Applied Sciences 7(2), 1882-1889.

Stott K, Mohammed C. 2004 - Specialty mushroom production systems: maitake and morel. Retrieved from:

http://citeseerx.ist.psu.edu/viewdoc/ownload?doi=10.1.1.546.9628\&rep=rep1\&type=pdf.

Shnyreva AV, Shnyreva AA, Espinoza C, Padron JM, Trigos A. 2018 - Antiproliferative activity and cytotoxicity of some medicinal wood-destroying mushroom from Russia. International Journal of Medicinal Mushrooms 20(1), 1-11.

Syahmi ARMS, Vijayaratha S, Sasidharan LY, Latha YPJ et al. 2010 - Acute oral toxicity of brine shrimp lethality of Elaeis guineensis method extract. Molecules 15, 8111-8112.

Thongklang N, Hyde KD, Bussaban B, Lumyong S. 2010 - Culture condition, inoculum production and host response of a wild mushroom, Phlebopus portentosus strain CMUHH121-005. Maejo International Journal of Science and Technology 5(3), 413-425. 
Umesha S, Naranayaswamy B. 2016 - Growth promoting substances and mineral elements in desiccated coconut mills (DC) coconut water. International Journal of Current Microbiology and Applied Sciences 5(4), 532-538.

Ware M. 2017 - What is the nutritional value of mushroom? Medical News Today. Retrieved from https://www.medicalnewstoday.com/articles/278858.php.

Wasser SP. 2010 - Medicinal mushroom science: history, current status, future trends, and unsolved problems. International Journal of Medicinal Mushrooms 12(1), 1-16.

Wasser SP. 2014 - Medicinal mushroom science: Current perspectives, advances, evidences, and challenges. Biomedical Journal 35(6), 516-528.

Wu HT, Lu F, Su Y, Ou H et al. 2014 - In vivo and in vitro anti-tumor effects of fungal extracts. Molecules 19, 2546-2556.

Younis A, Stewart J, Wu FS, Shikh HE et al. 2014 - Cytotoxic activity of edible mushrooms extracts against tumor cell lines. International Journal of Science and Technology 3(11), 736749.

Zhu Na L, Shan H, Guo H. 2011 - The study of Laricifomes officinalis optimization of solid medium and establish of culture conditions. Anhui Agricultural Science Bulletin 1(2). 